\title{
Antioxidant, Antibacterial and Antifungal Activities of Different Extracts of Silybum marianum Collected from Duhok (Iraq)
}

\author{
Falah Saleh Mohammed (iD),*, Mustafa Pehlivan (iD) ${ }^{2}$, Mustafa Sevindik ${ }^{(D)} 3$
}

\author{
${ }^{1}$ Department of Biology, Faculty of Science, Zakho University, Duhok, Iraq \\ ${ }^{2}$ Nurdağı Vocational School, Gaziantep University, Gaziantep, Turkey \\ ${ }^{3}$ Department of Food Processing, Bahçe Vocational School, Osmaniye Korkut Ata University, Osmaniye, Turkey
}

\begin{abstract}
In this study, antioxidant, antibacterial and antifungal activities of Silybum marianum (L.) Gaertn. collected from Duhok (Iraq) were determined. Ethanol, methanol and dichloromethane extracts of the fruit part of plant were obtained. Antioxidant potential was determined with TAS and TOS kits using ethanol extracts. Antibacterial and antifungal activity were determined using agar dilution method. Antibacterial activity was determined against 6 bacterial strains (Staphylococcus aureus, S. aureus MRSA, Enterococcus faecalis, Escherichia coli, Pseudomonas aeruginosa and Acinetobacter baumannii). Antifungal activity was determined against Candida albicans, $C$. krusei and $C$. glabrata. As a result of the studies, it was determined that plant extracts have high antioxidant activity. It was also found to be effective against bacteria at $25-400 \mu \mathrm{g} / \mathrm{mL}$ concentrations. Plant extracts were found to be more effective against gram negative bacteria. It was found to be effective against Candida species at $400-800 \mu \mathrm{g} / \mathrm{mL}$ concentrations. As a result, it was determined that the fruit parts of plant could be a natural antioxidant and antibacterial source.
\end{abstract}

\section{ARTICLE HISTORY}

Received: June 23, 2019

Revised: September 25, 2019

Accepted: December 16, 2019

\section{KEYWORDS}

Antioxidant,

Antibacterial,

Antifungal,

Medicinal Plants,

Silybum marianum

\section{INTRODUCTION}

Traditional medicine practices are common in many parts of the world. It is particularly common in China, India, Japan, Pakistan, Sri Lanka and Thailand. In China, about $40 \%$ of medical consumption comes from traditional medicines [1]. Iraq, where the study material is collected, hosts many natural plants due to its geographical diversity and climatic conditions. Iraq is located north and east of the mountainous Turkey and Iran regions and has a similar geography. In Iraq, 363 medicinal plant species belonging to approximately 98 families and 270 genera have a natural distribution [2]. In this study, S. marianum plant collected from Duhok region of Iraq was selected as the material. S. marianum, a member of Asteraceae, is a one-year herbaceous plant. The plant spreads naturally in Europe, Africa and Asia [3]. In previous studies, antioxidant, hepatoprotective, protective effect against DNA damage, antiaging, anti-aflatoxin, antibacterial and immunomodulatory activities of $S$. marianum were

CONTACT: Falah Saleh Mohammed Department of Biology, Faculty of Science, Zakho University, Duhok, Iraq 
reported [4-8]. In this study, it was aimed to determine the antioxidant, oxidant, antibacterial and antifungal activities of $S$. marianum fruit parts. $S$. marianum is consumed extensively by local people. Therefore, it was aimed to determine the antioxidant activity and activity of the plant. In addition, by determining oxidant level and oxidative stress index, it was aimed to determine the oxidative risk status in consumption.

\section{MATERIAL and METHODS}

Samples of S. marianum were collected from Iraq's Duhok-Bamarne region. Flora of Iraq was used to identify the plant [9]. Herbarium specimens were collected at Zakho University, Faculty of Arts and Sciences, Department of Biology herbarium.

\subsection{Laboratory studies}

Plant samples collected from the field were brought to the laboratory under appropriate conditions. The samples were allowed to dry in a shade and breathing environment. Dried marianum samples were cut and pulverized. $30 \mathrm{~g}$ of the fruit parts of the plant were extracted with soxhlet extractor with ethanol $(\mathrm{EtOH})$, methanol $(\mathrm{MeOH})$ and dichloromethane (DCM) at $50{ }^{\circ} \mathrm{C}$ for about 6 hours. The extracts obtained were concentrated by rotary evaporator.

\subsection{Antioxidant, Oxidant and Oxidative stress Tests}

The antioxidant and oxidant values of EtOH extracts of $S$. marianum were determined using Rel Assay TAS and TOS kits [10,11]. Trolox was used as a calibrator for TAS tests. Hydrogen peroxide was used as a calibrator for TOS tests. Oxidative stress index (OSI) (Arbitrary Unit $=\mathrm{AU}$ ) value was determined according to the following formula.,

$$
\text { OSI (AU) }=\frac{\text { TOS, } \mu \text { mol } \mathrm{H}_{2} \mathrm{O}_{2} \text { equiv./L }}{\text { TAS, mmol Trolox equiv./L X } 10}
$$

\subsection{Antibacterial and Antifungal Activity Tests}

Antibacterial and antifungal activity capacities of EtOH, MeOH and DCM extracts of $S$. marianum were determined using agar dilution method. Minimal inhibitor concentrations (MICs) of the extracts were tested against standard bacterial and fungus strains. Staphylococcus aureus ATCC 29213, S. aureus MRSA ATCC 43300, Enterococcus faecalis ATCC 29212, Escherichia coli ATCC 25922, Pseudomonas aeruginosa ATCC 27853 and Acinetobacter baumannii ATCC 19606 were used for antibacterial activity. Candida albicans ATCC 10231, C. krusei ATCC 34135 ATCC 13803 and C. glabrata ATCC 90030 strains were used for antifungal activity. Bacterial strains were pre-cultured on Muller Hinton Broth medium. Candida strains were pre-cultured on RPMI 1640 Broth medium. Turbidity of bacteria and fungi was prepared according to McFarland 0.5 scale to obtain a standard inoculum. Plant extracts were tested at $12.5-800 \mu \mathrm{g} / \mathrm{mL}$ concentrations. Dilutions were made with distilled water. Fluconazole and Amphotericin B were used as reference drugs for Candida strains. Amikacin, Ampicillin and Ciprofloxacin were used as reference drugs for bacterial strains. The lowest concentration that prevents the growth of bacteria and fungi were determined as MIC [12-17].

\section{RESULTS and DISCUSSION}

\subsection{Antioxidant and Oxidant Potential}

Antioxidant-based drug formulations are used in the prevention and treatment of serious health problems such as atherosclerosis, stroke, diabetes, Alzheimer's disease and cancer $[18,19]$ Therefore, it is very important to determine the natural materials that can be used in 
antioxidant drug formulations. In this context, antioxidant and oxidant potentials of $S$. marianum were determined. In addition, oxidative stress status was determined due to TAS and TOS values. The values obtained are shown in Table 1 .

Table 1. Antioxidant, Oxidant status and Oxidative stress index of S. marianum

\begin{tabular}{lccc}
\hline & TAS $(\mathrm{mmol} / \mathrm{L})$ & TOS $(\mu \mathrm{mol} / \mathrm{L})$ & OSI $(\mathrm{TOS} /(\mathrm{TASx} 10))$ \\
\hline S. marianum & $5.767 \pm 0.128$ & $12.144 \pm 0.060$ & $0.211 \pm 0.003$ \\
\hline
\end{tabular}

Values are presented as mean $\pm \mathrm{SD}$; Experiments were made in 5 parallels

Different researchers in different parts of the world have reported that $S$. marianum has antioxidant activity. In a study conducted in Egypt, ethanol extracts of the air-dried plant material of $S$. marianum were used and reported to have high antioxidant activity [20]. Methanol and hexane extracts of $S$. marianum seeds were used in the study conducted in Greece. Seed extracts of $S$. marianum collected from 30 different regions of Greece have been reported to have antioxidant potential [21]. It was reported that ethanol and petroleum ether extract of the seeds of $S$. marianum collected from Turkey were the antioxidant potential [22]. In China, ethanol extracts of leaf, man stem, root, fruit receptacle and pappus of $S$. marianum were used. Main stem showed the highest antioxidant activity. The lowest antioxidant activity was determined in extracts of root and pappus parts. In addition, $S$. marianum has been reported to have strong antioxidant activity [23]. In a study conducted in Russia, ethanol extracts of fruit parts of $S$. marianum were reported to have antioxidant activity [24]. In our study, fruit parts of $S$. marianum were used and it was found to have antioxidant potential. TAS, TOS and OSI values of $S$. marianum were determined for the first time. In studies on different plant species, TAS value of Rosa canina collected from Turkey was reported $4.602 \mathrm{mmol} / \mathrm{L}$, TOS value was $6.294 \mu \mathrm{mol} / \mathrm{L}$ and OSI value 0.138 [25]. TAS value of Salvia multicaulis collected from Turkey was reported $6.434 \mathrm{mmol} / \mathrm{L}$, TOS value was $22.441 \mu \mathrm{mol} / \mathrm{L}$ and OSI value 0.349 [26]. TAS value of Rhus coriaria var. zebaria collected from Iraq (Duhok) was reported $7.342 \mathrm{mmol} / \mathrm{L}$, TOS value was $5.170 \mu \mathrm{mol} / \mathrm{L}$ and OSI value 0.071 [27]. TAS value of Mentha longifolia subsp. longifolia collected from Turkey was reported $3.628 \mathrm{mmol} / \mathrm{L}$, TOS value was $4.046 \mu \mathrm{mol} / \mathrm{L}$ and OSI value 0.112 [28]. Also, TAS values of Thermopsis turcica, Brassica rapa and Calendula officinalis were reported as $2.06,1.25$ and $5.55 \mathrm{mmol} / \mathrm{L}$, respectively [29-31]. The TAS value indicates the level of antioxidant compounds produced in the plant. The TOS value indicates the levels of oxidant compounds produced in the plant. OSI value indicates how much antioxidant compounds produced in plants suppress oxidant compounds. Compared to these studies, TAS value of $S$. marianum used in our study was higher than $M$. longifolia subsp. longifolia, $R$. canina, T. turcica, B. rapa and $C$. officinalis. It is lower than $R$. coriaria var. zebaria and S. multicaulis. TOS and OSI values of $S$. marianum was lower than $S$. multicaulis, $R$. canina and $R$. coriaria var. zebaria. Also TOS and OSI values of S. marianum was higher than $M$. longifolia subsp. longifolia. As a result, S. marianum has a high TAS value. In this context, it was determined that the fruit parts of $S$. marianum could be used as a natural antioxidant source.

\subsection{Antibacterial and Antifungal Activity}

Since ancient times, many plant species have been a source of medicine for humans. Evidence has been found that the Neanderthals who lived in Iraq 60.000 years ago used plants such as hollyhock. To date, plant species containing a lot of information on ethnobotany have been widely used. Today, almost half of the plant species used as medicines in the United States are used for antimicrobial purposes. Unconscious use of antibiotics in humans has led to the formation of resistant forms of microorganisms. For this reason, the antibiotics used in the market are insufficient in the fight against microorganisms [32,33]. In this context, 
determination of antimicrobial potential of plant species is very important. In this study, the lowest extract concentrations of $S$. marianum that prevent the growth of bacteria and fungi were determined. The findings are shown in Table 2.

Table 2. Antibacterial and Antifungal Activity of S. marianum

\begin{tabular}{lccccccccc}
\hline & $A$ & $B$ & $C$ & $D$ & $E$ & $F$ & $G$ & $H$ & $J$ \\
\hline EtOH & 100 & 100 & 400 & 25 & 50 & 100 & 400 & 400 & 400 \\
MeOH & 100 & 200 & 400 & 50 & 50 & 400 & 800 & 800 & 800 \\
DCM & 200 & 200 & 400 & 50 & 50 & 400 & 800 & 800 & 800 \\
Ampicillin & 1.56 & 3.12 & 1.56 & 3.12 & 3.12 & - & - & - & - \\
Amikacin & - & - & - & 1.56 & 3.12 & 3.12 & - & - & - \\
Ciprofloksasin & 1.56 & 3.12 & 1.56 & 1.56 & 3.12 & 3.12 & - & - & - \\
Flukanazol & - & - & - & - & - & - & 3.12 & 3.12 & - \\
Amfoterisin B & - & - & - & - & - & - & 3.12 & 3.12 & 3.12
\end{tabular}

*(A) S. aureus, (B) S. aureus MRSA, (C) E. faecalis, (D) E. coli, (E) P. aeruginosa, (F) A. baumannii, (G) C. glabrata, (H) C. albicans, (J) C. krusei

$* 800,400,200,100,50$ and $25 \mu \mathrm{g} / \mathrm{mL}$ extract concentrations

Previously, n-hexane extract of seeds of $S$. marianum collected from Turkey was reported to be effective against $P$. aeruginosa, E. coli, S. aureus, Salmonella typhi, Aspergillus niger and C. albicans at different concentrations [34]. Methanol, n-hexane and chloroform extracts of $S$. marianum collected from 10 different regions of Pakistan were reported to be effective against E. coli, Salmonella spp., Shigella spp., S. aureus and V. cholerae at different concentrations [35]. Aqueous and methanol extracts of $S$. marianum collected from Algeria were reported to be effective against $S$. aureus, E. coli, Klebsiella pneumoniae, P. aeruginosa, Enterobacter aerogenes and $C$. albicans at different concentrations [36]. In our study, $\mathrm{EtOH}, \mathrm{MeOH}$ and DCM extracts of fruit parts of $S$. marianum were used. EtOH extracts of plant showed the highest activity. Plant extracts were generally found to be more effective against gram negative bacteria (E. coli, P. aeruginosa and A. baumannii). Antifungal activity of plant extracts was found to be low. Plant extracts were found to be effective against bacterial species at 25-400 $\mu \mathrm{g} / \mathrm{mL}$ concentrations. It was found to be effective against Candida species at $400-800 \mu \mathrm{g} / \mathrm{mL}$ concentrations. As a result, it was determined that the fruit parts of $S$. marianum could be a natural antibacterial agent against the tested microorganisms.

\title{
4. CONCLUSION
}

In this study, antioxidant, oxidant, antibacterial and antifungal activities of fruits parts of $S$. marianum collected from Duhok (Iraq) region were determined. Fruit parts of the plant have been found to have high antioxidant activity. In addition, plant extracts were found to be more effective against gram negative bacteria. The antifungal activity of the plant extracts were found to be low. As a result, it was determined that the fruit parts of $S$. marianum could be natural antioxidant and antibacterial agent.

\section{Orcid}

\author{
Falah Saleh MOHAMMED (iD https://orcid.org/0000-0001-9083-1876 \\ Mustafa PEHLIVAN (D) https://orcid.org/0000-0002-8277-6085 \\ Mustafa SEVINDIK (i) https://orcid.org/0000-0001-7223-2220
}




\section{REFERENCES}

[1]. Dar, R.A., Shahnawaz, M., Qazi, P.H. (2017). General overview of medicinal plants: A review. J. Pharmacol., 6(6), 349-351.

[2]. Al-Douri, N.A. (2014). Some important medicinal plants in Iraq. Int. J. Adv. Herb. Altern. Med., 2, 10-20.

[3]. Katar, D., Yaman, H., Subaș1, İ., Arslan, Y. (2013). Determination of some characteristics of M1 seedling of milk thistle (Silybum marianum (L.) Gaertn.) obtained by treatment of different doses of gama irradiation. SDÜ Ziraat Fak. Derg., 8(1), 78-83.

[4]. Zhao, F., Li, X.H. (2015). Evaluation of Immunomodulatory Activity of Silymarin Extract from Silybum Marianum in Mice of Health Food. Adv. J. Food Sci. Technol., 8(4), 278282.

[5]. Surai, P.F. (2015). Silymarin as a natural antioxidant: an overview of the current evidence and perspectives. Antioxidants, 4(1), 204-247.

[6]. Alhidary, I.A., Rehman, Z., Khan, R.U., Tahir, M. (2017). Anti-aflatoxin activities of milk thistle (Silybum marianum) in broiler. Worlds Poult. Sci. J., 73(3), 559-566.

[7]. Yue, J., Zhu, Z., Li, X. (2017). Antibacterial activity of protease hydrolysates isolated from Silybum marianum. Curr. Sci., 113(3), 00113891

[8]. Zhu, S.Y., Jiang, N., Jie, T.U., Yang, J., Zhou, Y. (2017). Antioxidant and Anti-aging Activities of Silybum Marianum Protein Hydrolysate in Mice Treated with Dgalactose. Biomed Environ Sci, 30(9), 623-631.

[9]. Townsend, C.C., Guest, E. (1966-1985). Flora of Iraq. vols. 1-9. Ministry of Agriculture and Agrarian Reform, Baghdad.

[10]. Erel, O. (2004). A novel automated direct measurement method for total antioxidant capacity using a new generation, more stable ABTS radical cation. Clin. biochem., 37(4), 277-285.

[11]. Erel, O. (2005). A new automated colorimetric method for measuring total oxidant status. Clin. Biochem., 38(12), 1103-1111.

[12]. Bauer, A.W., Kirby, W.M., Sherris, J.C., Turck, M. (1966). Antibiotic susceptibility testing by a standardized single disk method, Am. J. Clin. Pathol., 45, 493-96.

[13]. Hindler, J., Hochstein, L., , Howell, A. (1992). Preparation of routine media and reagents used in antimicrobial susceptibility testing. Part 1. McFarland standards, 5.19.1-5.19.6. In H. D. Isenberg (ed) Clinical microbiology procedures handbook, vol. 1. American Society for Microbiology, Washington, D.C.

[14]. CLSI (The Clinical and Laboratory Standards Institute). (2012). Antimicrobial Susceptibility Testing of Anaerobic Bacteria; Approved Standard-Eighth Edition (M11A8).

[15]. EUCAST (European Committee on Antimicrobial Susceptibility Testing). (2014). Breakpoint tables Fungal isolate for interpretation of MICs. Version 7.0.

[16]. Matuschek, E., Brown, D.F., Kahlmeter, G. (2017). Development of the EUCAST disk diffusion antimicrobial susceptibility testing method and its implementation in routine microbiology laboratories, Clin. Microbiol. Infect., 20, 255-266.

[17]. EUCAST (European Committee on Antimicrobial Susceptibility Testing). (2015). Breakpoint tables for Bacteria interpretation of MICs and zone diameters. Version 5.0

[18]. Khalaf, N.A., Shakya, A.K., Al-Othman, A., El-Agbar, Z., Farah, H. (2008). Antioxidant activity of some common plants. Turk. J. Biol., 32(1), 51-55.

[19]. Dastan, S.D., Gulhan, M.F., Selamoglu, Z., Dastan, T. (2017). The determination of different effective concentration of ethanolic extract of bee pollen on biochemical analysis in liver, spleen and heart tissues of rainbow trout, Oncorhynchus mykiss (Walbaum, 1792). Iran. J. Fish. Sci., 16(1), 326-340. 
[20]. Ramadan, S.I., Shalaby, M.A., Afifi, N., El-Banna, H.A. (2011). Hepatoprotective and antioxidant effects of Silybum marianum plant in rats. Int. J. Agro. Veter. Med. Sci., 5, 541-47.

[21]. Arampatzis, D.A., Karkanis, A.C., Tsiropoulos, N.G. (2019). Silymarin content and antioxidant activity of seeds of wild Silybum marianum populations growing in Greece. Ann. Appl. Biol., 174(1), 61-73.

[22]. Serçe, A., Toptancı, B.Ç., Tanrıkut, S.E., Altaş, S., Kızıl, G., Kızı1, S., Kızı1, M. (2016). Assessment of the Antioxidant Activity of Silybum marianum Seed Extract and Its Protective Effect against DNA Oxidation, Protein Damage and Lipid Peroxidation. Food Technol. Biotechnol., 54(4), 455.

[23]. Sun, J., Li, X. H., Yu, X. L. (2016). Antioxidant activities, total flavonoids and phenolics content in different parts of silybum marianum 1. plants. Chemical Engineering Transactions, 55, 37-42.

[24]. Kurkin, V. (2016). Antioxidant Activity of Flavolignans from Silybum marianum (L). Gaertn. Fruits. Res. Rev. J. Pharma. Phytochem., 4(1), 50-53

[25]. Pehlivan, M., Mohammed, F. S., Sevindik, M., Akgul, H. (2018). Antioxidant and oxidant potential of Rosa canina. Eurasian Journal of Forest Science, 6(4), 22-25.

[26]. Pehlivan, M., Sevindik, M. (2018). Antioxidant and antimicrobial activities of Salvia multicaulis. Turk. J.A.F. Sci. Tech, 6(5), 628-631.

[27]. Mohammed, F.S., Akgul, H., Sevindik, M., Khaled, B.M.T. (2018). Phenolic content and biological activities of Rhus coriaria var. zebaria. Fresen. Environ. Bull., 27(8), 56945702.

[28]. Sevindik, M., Akgul, H., Pehlivan, M., Selamoglu, Z. (2017). Determination of therapeutic potential of Mentha longifolia ssp. longifolia. Fresen Environ Bull, 26(7), 4757-4763.

[29]. Aksoy, L., Kolay, E., Ağılönü, Y., Aslan, Z., Kargığlu, M. (2013). Free radical scavenging activity, total phenolic content, total antioxidant status, and total oxidant status of endemic Thermopsis turcica. Saudi J. Biol. Sci., 20(3), 235-239.

[30]. Gul, S., Ahmed, S., Gul, H., Shad, K. F., Zia-Ul-Haq, M., Badiu, D. (2013). The antioxidant potential of Brassica rapa L. on glutathione peroxidase, superoxide dismutase enzymes and total antioxidant status. Rev. Rom. Med. Lab., 21(2), 161-169.

[31]. Verma, P.K., Raina, R., Sultana, M., Singh, M., Kumar, P. (2016). Total antioxidant and oxidant status of plasma and renal tissue of cisplatin-induced nephrotoxic rats: protection by floral extracts of Calendula officinalis Linn. Renal failure, 38(1), 142-150.

[32]. Goud, M.J.P., Komraiah, A., Rao, K., Ragan, A., Raju, V.S., Charya, M.S. (2008). Antibacterial activity of some folklore medicinal plants from South India. Afr. J. Tradit. Complement. Altern. Med., 5(4), 421-426.

[33]. Thangavel, K., Sasikala, M., Maridass, M., Nadu, T. (2008). In vitro antibacterial potential of Aegle marmelos (L.) callus extract. Pharmacol. Online, 3, 190-196.

[34]. Yaldiz, G. (2017). Effects of potassium sulfate [K2SO4] on the element contents, polyphenol content, antioxidant and antimicrobial activities of milk thistle [Silybum marianum]. Pharmacogn. Mag., 13(49), 102.

[35]. Ahmad, N., Perveen, R., Jamil, M., Naeem, R., Ilyas, M. (2015). Comparison of antimicrobial properties of Silybum marianum (L) collected from ten different localities of Khyber Pakhtunkhwa Pakistan and diversity analysis through RAPDs pattern. Int. J. Plant. Sci. Ecol., 1(6), 241-5.

[36]. Zaouia, K., Segni, L., Noureddine, G., Redha, O. M. (2010). Antimicrobial activity of nine medicinal plants growing in the south of Algeria. Ann. Biol. Res., 1(4), 145-147. 